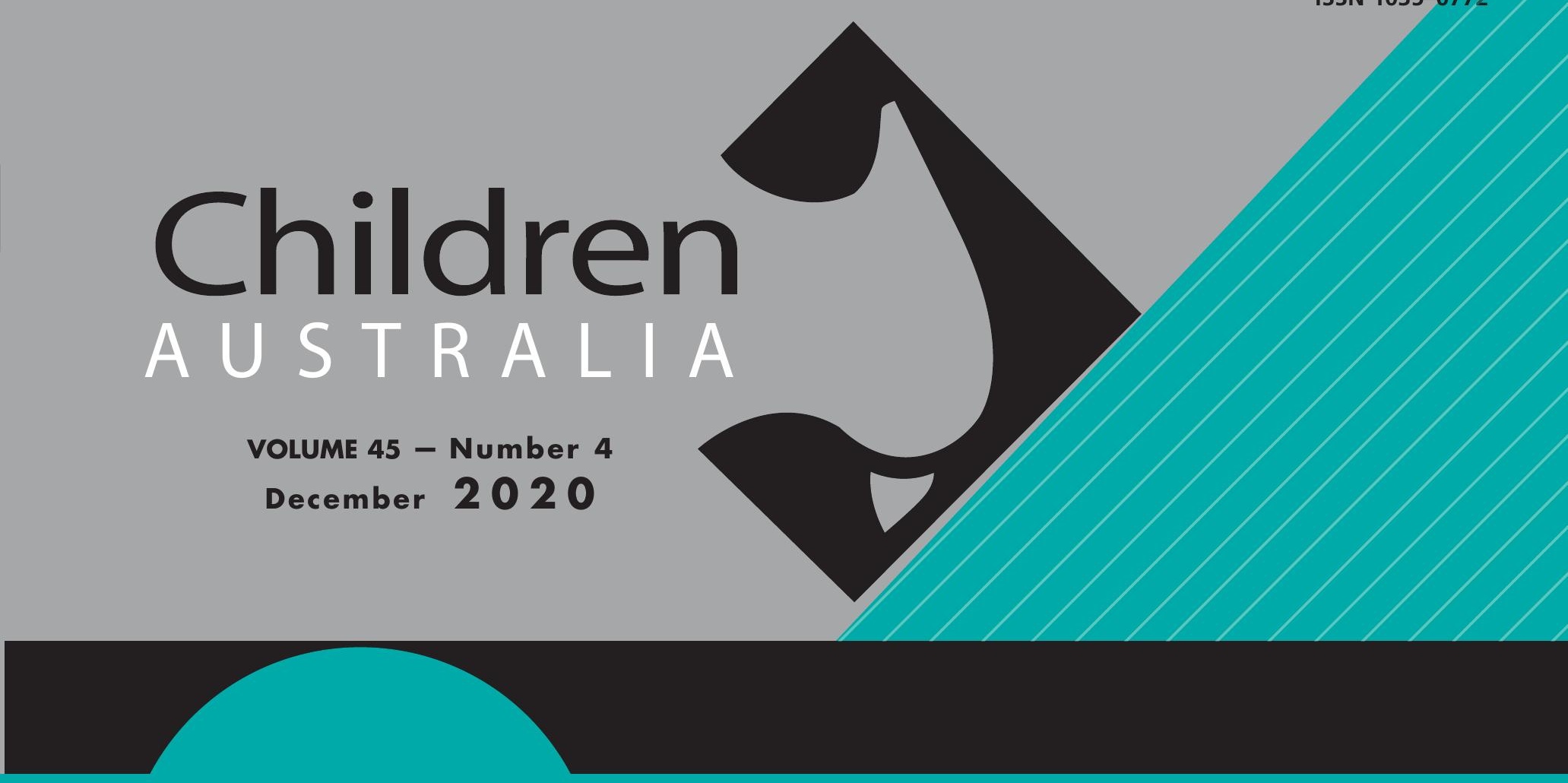




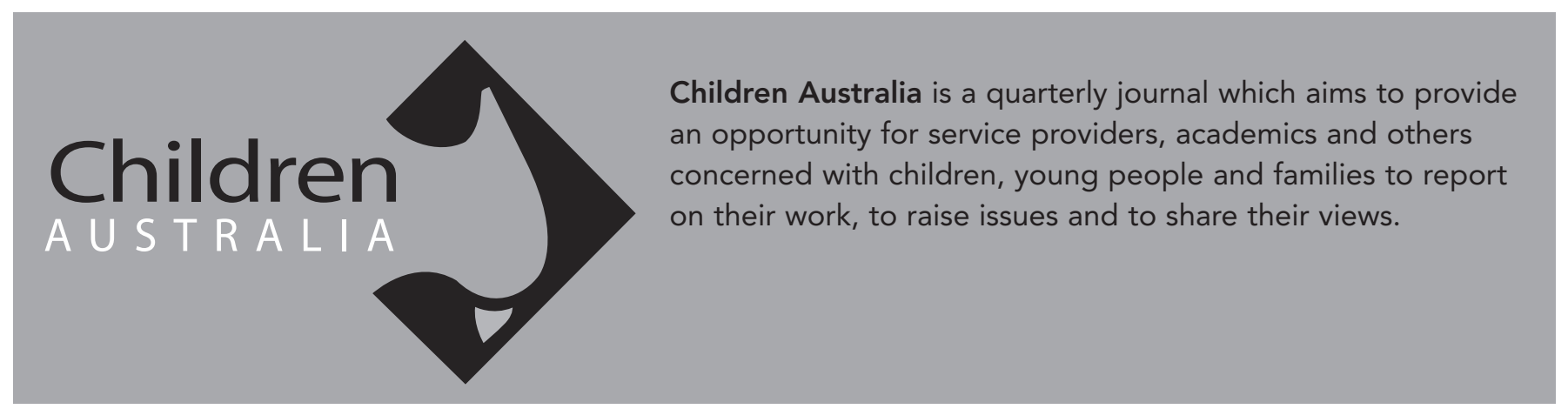

\section{SUBSCRIPTIONS and ENQUIRIES}

For subscription information and general enquiries, or to advise change of contact details, please contact: journals@cambridge.org

\section{GUIDELINES FOR AUTHORS}

Guidelines for authors wishing to submit material to be considered for publication in Children Australia can be found on the inside of the back cover.

Manuscripts, book reviews and editorial communications can be submitted through ScholarOne: https:// mc.manuscriptcentral.com/cha

The views expressed in Children Australia are those of the authors, and are therefore not necessarily endorsed by the Editor or members of the editorial board.

\section{SUBSCRIPTION RATES 2020 \\ This journal is published 4 times per year. \\ The institutional rates (excluding VAT) are:

$\begin{array}{lcc} & \text { Print and online } & \text { Electronic Only } \\ \text { N America } & 287 \text { USD } & 270 \text { USD } \\ \text { UK and ROW } & 185 \text { GBP } & 175 \text { GBP }\end{array}$ \\ EU subscribers (outside the UK) who are not regis- tered for VAT should add VAT at their country's rate. VAT registered subscribers should provide their VAT registration number. Prices include delivery by air when appropriate. Japanese prices for institutions are available from Kinokuniya Company Ltd, P.O. Box 55, Chitose, Tokyo 156, Japan. \\ Orders and subscription enquiries should be addressed to: \\ Cambridge University Press, Journals Fulfillment \\ Department, UPH, Shaftesbury Road, Cambridge CB2 8BS, UK. \\ Orders from N America should be addressed to: Cambridge University Press, 1 Liberty Plaza, Floor 20, New York, NY 10006, USA \\ Children Australia and all other Cambridge Journals can be found at cambridge.org/core}

The support of La Trobe University is gratefully acknowledged

Permission to copy (for users in the USA) is available from Copyright Clearance Center, http://www.copyright.com, email:info@copyright.com

\section{EDITORS}

Dr Jennifer Lehmann

La Trobe University

Dr Rachael Sanders

La Trobe University

\section{EDITORIAL CONSULTANTS}

Angela Abela

University of Malta, Malta

Frank Ainsworth

James Cook University, Australia

Nicola Atwool

University of Otago, New Zealand

Muriel Bamblett

Victorian Aboriginal Child Care Association (VACCA), Australia Helen Buckley

Trinity College Dublin, Ireland

Elizabeth Fernandez

University of New South Wales, Australia

Margarita Frederico

La Trobe University, Australia

Michael Gaffney

University of Otago, New Zealand

Susan Gair

James Cook University, Australia

Chris Goddard

Adjunct Professor in Education, Arts and Social

Sciences, University of South Australia, Australia

Visiting Professor in Social Work at the University of

Hertfordshire, UK

Anna Gupta

Royal Holloway University of London, UK

Leesa Hooker

LaTrobe University, Australia

Wynne Sandra Korr University of Illinois, USA

Antoinette Lombard, University of Pretoria, South Africa

Liana le Roux University of Pretoria, South Africa

Jonathon Sargeant Australian Catholic University, Australia

Chris-Maree Sultmann Encompass Family \& Community, Australia

David Vicary

Children's Protection Society, Australia
(C) Published by Cambridge University Press. All rights reserved. No part of this publication may be reproduced, in any form or by any means, electronic, photocopying, or otherwise, without permission in writing from Cambridge University Press. 


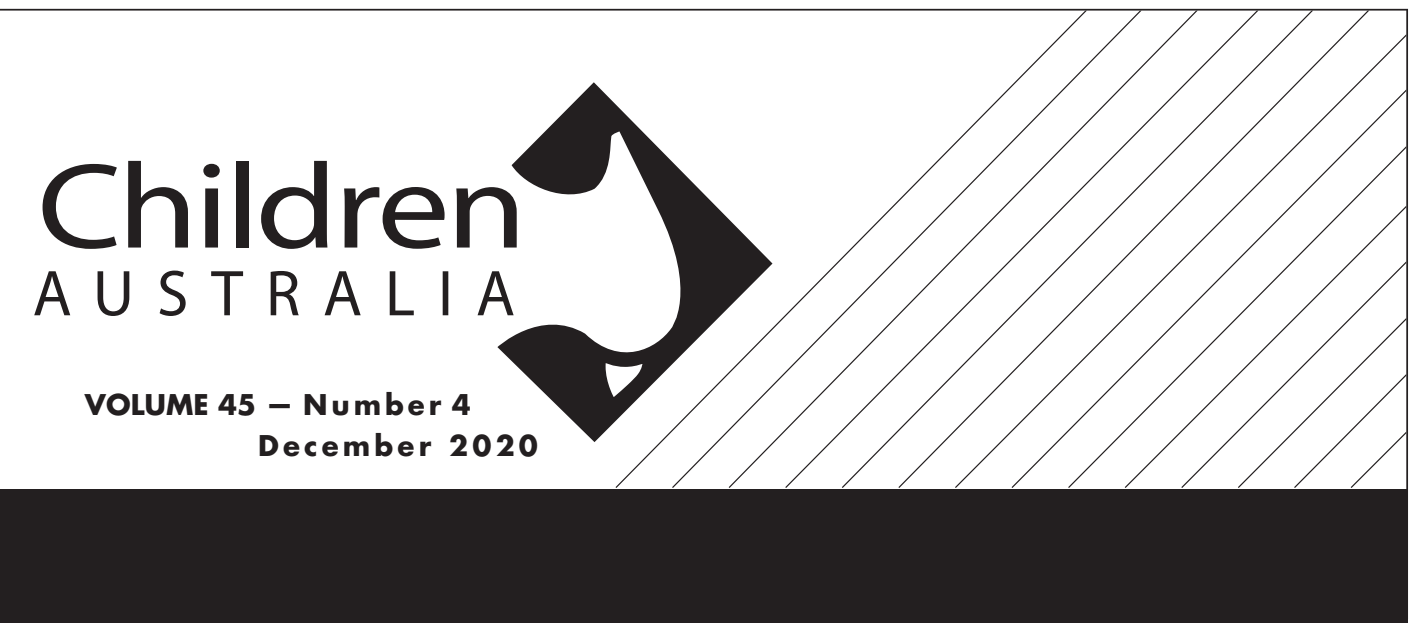

\section{Contents}

\section{EDITORIAL}

The end of an era

Jennifer Lehmann

Poverty and child abuse and neglect

Frank Ainsworth, Jennifer Lehmann and Rachael Sanders

\section{PART A: THEMED ISSUE: POVERTY AND CHILD ABUSE}

\section{ARTICLES}

The social and economic origins of child abuse and neglect

Frank Ainsworth

Poverty is the problem - not parents: so tell me, child protection worker, how can you help?

Kylie Bennett, Andrew Booth, Susan Gair, Rose Kibet and Ros Thorpe

Infant removal and the lack of representation for parents

Celine Harrison, Carol Bahemia and Debbie Henderson

Zimbabwe's poverty and child sexual abuse

Noel Garikai Muridzo and Victor Chikadzi

Cash transfer and professional care for tackling child poverty and neglect in Italy

Copyright in all articles rests with authors. However, a limited set of permanent copyright permission licences has been granted by authors to the publisher to allow publication in this journal. Rights in the reproduction and distribution of the published articles as visual facsimiles of this published edition by either mechanical or digital means is controlled by the publisher and any distributions by CAL for copying of an author's work therefore are due to the publisher. All other rights in the words contained in this edition are controlled by the authors. Authors are therefore free to adapt and/or republish the words making up their own articles either online or in print, including academic repositories. 


\section{Children \\ VOLUME 45 - Number 4 \\ 2020}

\section{PART B: REGULAR ISSUE}

\section{PRACTICE COMMENTARY}

Human Services workers' experiences of rapidly moving to Telehealth

Rachael Sanders

\section{REVIEWS}

Care leavers, ambiguous loss and early parenting: explaining high rates of pregnancy and parenting amongst young people transitioning from out-of-home care

Jade Purtell, Philip Mendes and Bernadette J. Saunders

The educational outcomes of children in care - a scoping review

Stephan Lund and Cathy Stokes

Evaluating frameworks for practice in mainstream primary school classrooms catering for children with developmental trauma: an analysis of the literature

Simone Collier, India Bryce, Karen Trimmer and Govind Krishnamoorthy

Necessary and good: a literature review exploring ethical issues for online counselling with children and young people who have experienced maltreatment

Mary Jo McVeigh and Susan Heward-Belle

Filicide: the Australian story

Thea Brown, Danielle Tyson and Paula Fernandez Arias

What do young people worry about? A systematic review of worry theme measures of teen and preteen individuals

Marcin Owczarek, Grainne McAnee, Donal McAteer and Mark Shevlin

\section{ARTICLES}

'It was daunting. I was 18 and I left residential care and there was no support whatsoever': a scoping study into the transition from out-of-home-care process in Tasmania, Australia Renée O'Donnell, Ann MacRae, Melissa Savaglio, Dave Vicary, Rachael Green (nee Cox), Philip Mendes, Gary Kerridge, Graeme Currie, Susan Diamond and Helen Skouteris 


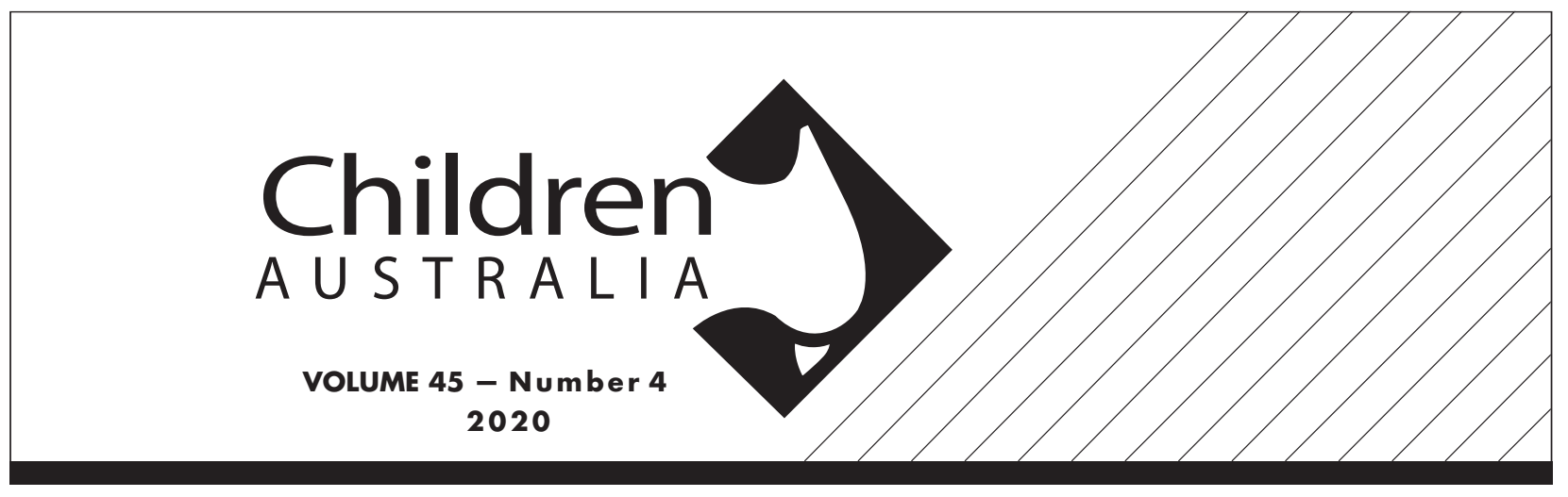

Evaluation of the Cradle to Kinder programme for Aboriginal mothers and their children:

perspectives from the women and their workers

305

Renée O'Donnell, Muriel Bamblett, Gabrielle Johnson, Sue-Anne Hunter, Kerry Stringer, Shantai Croisdale,

Bengianni Pizzirani, Darshini Ayton, Melissa Savaglio and Helen Skouteris

Demonstrating the effectiveness of a residential education programme for disengaged young people:

a preliminary report

Paul Mastronardi, Frank Ainsworth and Jonathan C. Huefner

Parents' experiences and use of parenting resources during the transition to parenthood

Rachael Sanders, Jennifer Lehmann and Fiona Gardner

The need for a community-led, holistic service response to Aboriginal young people with cognitive

disability in remote areas: a case study

326

Ruth McCausland and Leanne Dowse

\section{BOOK REVIEWS}

Blame, culture and child protection

Frank Ainsworth

A history of the Personal Social Services in England. Feast, Famine and the Future

Frank Ainsworth

Children Australia is a refereed journal with the majority of papers being peer reviewed to assess their suitability for publication. Peer-reviewed papers are expected to meet contemporary academic standards. However, at the discretion of the editor, papers which have not been reviewed are published from time to time. Such papers may include short commentaries on practice issues that are essentially based on observation and experience; reports on program approaches, initiatives or projects that are both short and unreferenced; historical overviews; or short papers that respond to a peer-reviewed article published in an earlier edition which adds to informed debate or provides an alternative perspective. It is anticipated that no more than one such paper would be included in each issue.

In order to clarify which articles have been reviewed and which have not, we now include a symbol at the end of each article as follows: $\mathbf{\square}=$ peer-reviewed article; $\square=$ non-reviewed article 